\title{
Characterization techniques for materials' properties measurement
}

\author{
Hussein KASSEM, Valérie VIGNERAS and Guillaume LUNET \\ University of Bordeaux, IMS-Bordeaux Laboratory
}

France

\section{Introduction}

The electromagnetic properties of materials are defined from the two following constitutive parameters: permittivity, $\varepsilon$, and permeability, $\mu$; ' $\varepsilon$ ' indicates how the medium reacts when an electric field is applied (field $E$ of the electromagnetic wave), whereas $\mu$ indicates how the material behaves further to a magnetic excitation (field $\mathrm{H}$ of the electromagnetic wave). To take into account the losses that occur in any material, permittivity and permeability need both to be expressed by complex values: $\varepsilon=\varepsilon^{\prime}-j \varepsilon^{\prime \prime}, \mu=\mu^{\prime}-j \mu^{\prime \prime}$.

But already, what represent these parameters?

As, during this chapter we will mostly be interested by the measurement of the permittivity of materials, we'll going to explain the dielectric properties and similar explanation can be mounted for the magnetic properties.

In general, a material is classified as "dielectric" if it has the ability to store energy when an external electric field is applied. Lets imagine a DC voltage source placed across a parallel plate capacitor, we'll have the ability to store an electric charge and called the capacitance ' $C$ ' defined to be the charge ' $q$ ' per applied voltage ' $V$ ' that is $C_{0}=q / V$, where $C$ is given in coulombs per volt or farad. The capacitance is higher, the larger the area $\mathrm{A}$ of the plates and the smaller the distance $\mathrm{L}$ between them. And so, $\mathrm{C}_{0}=\varepsilon_{0}(\mathrm{~A} / \mathrm{L})$, where $\varepsilon_{0}$ is a universal constant having the value of $8.85 \times 10-12 \mathrm{~F} / \mathrm{m}$ (farad per meter) and is known by the name permittivity of empty space (or of vacuum).

Now lets insert a material between the plates, the new value of the capacitance ' $C$ ' is increased by a factor $\varepsilon=C / C_{0}$, which lead to $C=\varepsilon \varepsilon_{0}(A / L)$, where ' $\varepsilon$ ' represents the magnitude of the added storage capability. It is called the (unit less) dielectric constant (or occasionally the relative permittivity $\varepsilon r$ ). So, for the complex representation $\varepsilon_{r}=\varepsilon_{r}^{\prime}-j \varepsilon_{r}^{\prime \prime}$, the real part of permittivity $\left(\varepsilon_{\mathrm{r}}^{\prime}\right)$ is a measure of how much energy from an external electric field is stored in a material. The imaginary part of permittivity $\left(\varepsilon_{r}^{\prime \prime}\right)$ is called the loss factor and is a measure of how dissipative or lossy a material is to an external electric field. The imaginary part of permittivity $\left(\varepsilon_{r}{ }^{\prime \prime}\right)$ is always greater than zero and is usually much smaller than $\left(\varepsilon_{r}^{\prime}\right)$. the loss is usually denoted by: the loss tangent or 'tan $\delta^{\prime}$ which is defined as the ratio of the imaginary part of the dielectric constant to the real part. The loss tangent ' $\tan \delta$ ' is called tan delta, tangent loss or dissipation factor. 
Dielectric materials, that is, insulators, possess a number of important electrical properties which make them useful in the electronics industry. A type of dielectric materials is the ferroelectric materials, such as barium titanate. These materials exhibit spontaneous polarization with out the presence of an external electric field. Their dielectric constants are orders of magnitude larger than those of normal dielectrics. Thus, they are quite suitable for the manufacturing of small-sized, highly efficient capacitors. Moreover, ferroelectric materials retain their state of polarization even after an external electric field has been removed. Therefore, they can be utilized for memory devices in computers, etc.

Taken together, these properties have been the key to the successful use of ceramics in microwave and optical domains. They are widely studied nowadays as potential replacements for semiconductors in modern tunable microwave devices such as tunable filters, phase-shifters, frequency mixers, power dividers, etc. This material integration, often in thin layers, for the miniaturization of components and circuits for telecommunications requires a preliminary knowledge of the dielectric and/or magnetic characteristics of these materials.

Accurate measurements of these properties can provide scientists and engineers with valuable information to properly incorporate the material into its intended application for more solid designs or to monitor a manufacturing process for improved quality control.

Variety of instruments, fixtures, and software to measure the dielectric and magnetic properties of materials are offered by the industries, such as network analyzers, LCR meters, and impedance analyzers range in frequency up to $325 \mathrm{GHz}$. Fixtures to hold the material under test (MUT) are available that are based on coaxial probe, coaxial/waveguide transmission line techniques, and parallel plate. Most of these serve to measure massive materials, but, with the advance in technology and miniaturizations of devices, thin film measurement became essential but still not yet industrialized.

In general, to measure the permittivity and permeability of a given material, a sample is placed on the path of a traveling electromagnetic wave, either in free space or inside one of the propagation structure mentioned. One can also put this sample at an antinode of the electric or magnetic field of a stationary wave, for example inside a resonator cavity. Reflection and transmission coefficients of the experimental device are directly related to electromagnetic properties of the material of concern; they are measured using a network analyzer. Then, the sample permittivity and permeability are determined from these coefficients and from the electromagnetic analysis of the discontinuities created within the material.

To select a characterization method, one should consider:

- the exploited frequency range,

- the physical properties of the material of concern: is it magnetic or not, low-loss or lossy, isotropic or anisotropic, homogeneous or heterogeneous, dispersive or not? And

- the shape and nature of the available samples, i.e. plate or thin films, liquid or solid, elastomeric or granular.

At microwave frequencies, generally higher than $1 \mathrm{GHz}$, transmission-line, resonant cavity, and free-space techniques are commonly used. Here we present a brief coverage of both established and emerging techniques in materials characterization. 


\section{Methods of characterizations}

A state of the art on the techniques for electromagnetic characterization of dielectric materials is carried out. The most common methods are classified into their main categories: resonant and broadband.

\subsection{Massive materials measurements}

(a) Coaxial probe

In a reflection method, the measurement fixture made from a transmission line is usually called measurement probe or sensor. There is a large family of coaxial test fixtures designed for dielectric measurements and those are divided into two types: open-circuited reflection and short-circuited reflection methods.
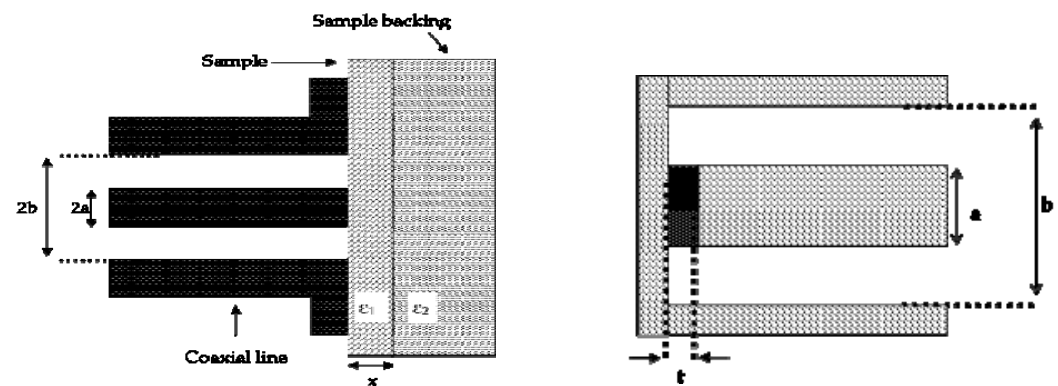

Fig 1. (left) open ended coaxial probe, (right) short ended coaxial probe test fixture

Open-ended coaxial test fixtures (OCP) (Fig 1-left) are the most popular techniques for measuring of complex dielectric permittivity of many materials. Non-destructive, broadband (RF and microwave ranges), and high-temperature ( $<=1200 \mathrm{C}$ ) measurements can be preformed with this method using commercially available instrumentation. The measurements are performed by contacting one flat surface of the specimen or by immersing the probe in the liquid sample. These techniques (Baker-Jarvis \& Janezic, 1994; chen et al. 1994) has been widely used due to the convenience of using one port measurements to extract dielectric parameters and the relatively simple setup. Furthermore, minimal sample preparation is required compared to other techniques, such as the waveguide technique which will be seen later and which requires precisely machined bulk samples and is generally classified as a destructive testing method.

There are two basic approaches to the determination of complex permittivity from the measurements of the coaxial line open-circuit reflection coefficient; a rigorous solution (Baker-Jarvis \& Janezic, 1994; chen et al. 1994) of the electromagnetic field equations, and the lumped equivalent approach utilising an admittance circuit to represent the probe fringing fields. Nevertheless, theoretical formulations for the open-ended coaxial probe assume that the MUT extends to infinity in the longitudinal and transverse directions, which is practical when considering finite thin samples.

(chen et al. 1994) presented a method using an open coaxial probe where the material to be measured (MUT) is backed by an arbitrary medium of semi-infinite thickness in a bi-layer configuration (Fig 1-a). The coaxial line is considered to have an infinite flange extending in 
the radial direction, while the MUT is considered to be linear, isotropic, homogeneous and nonmagnetic in nature. It is further assumed that only TEM mode fields exist at the probe aperture. The total terminal capacitance $\mathrm{C}_{\mathrm{T}}$ can be represented by:

$$
\mathrm{C}_{\mathrm{T}}=\mathrm{C}_{\mathrm{f}}+\mathrm{C}_{01}+\mathrm{C}_{02}
$$

Where $C_{f}$ is the capacitance inside a Teflon-filled coaxial line while $C_{01}$ represents the capacitance due to the fringing field outside the coaxial line into the finite sample and $\mathrm{C}_{02}$ represents the capacitance of the fringing field into the infinitely thick medium that is used to back the sample.

The final expression for the permittivity of the MUT after incorporating the error network is expressed as:

$$
\varepsilon_{1}=\frac{a \rho+b}{c \rho+1}=\frac{g_{1}\left(f, x, D, \varepsilon_{2}\right) \rho+g_{2}\left(f, x, D, \varepsilon_{2}\right)}{g_{3}\left(f, x, D, \varepsilon_{2}\right) \rho+1}
$$

Where $\varepsilon_{1}$ and $\varepsilon_{2}$ are the dielectric constants of the MUT and the infinite medium (dielectric backing), respectively, $x$ is the thickness of the MUT and D represents an empirical parameter with dimensions of length, $\rho$ is the measured reflection coefficient, $a, b$ and $c$ are complex coefficients that are functions of frequency $f$. corresponding to functions g1, g2 and g3 respectively which are, in turn, dependent on parameters $f, x, D$ and $\varepsilon_{2}$. To extract $\varepsilon 1$, three simultaneous equations are required to determine $a, b$ and $c$, which are obtained by measuring the reflection coefficients of three materials with known dielectric properties. The model is valid at frequencies for which the line dimensions are small compared to the wavelength.

The OCP method is very well suited for liquids or soft solid samples. It is accurate, fast, and broadband (from 0.2 to up to $20 \mathrm{GHz}$ ). The measurement requires little sample preparation. A major disadvantage of this method is that it is not suitable for measuring materials with low dielectric property (plastics, oils, etc.) nor for thin films.

Short-circuited reflection: In these methods, a piece of sample is inserted in a segment of shorted transmission line. An interesting method is presented by (Obrzut \& Nozaki, 2001) (Fig 1-right). A dielectric circular film (disk) specimen of thickness $t$ is placed at the end of the center conductor of a coaxial airline. The diameter of the specimen ' $a$ ' matches that of the central conductor and forms a circular parallel-plate capacitor terminating the coaxial line. The incoming transverse-electromagnetic (TEM) wave approaches the sample section through the coaxial line. The lumped capacitance model applies to this structure at higher frequencies and still satisfies the quasi-static conditions as long as the length of the propagating wave is much larger than the film thickness. The structure is electrically equivalent to a network in which the dielectric film can be viewed as a transmission line inserted between 2 matched transmission lines. The permittivity of the sample material is written as follows:

$$
\varepsilon^{*}=\frac{G_{s}}{j \omega C_{p}} \frac{1-S_{11}}{1+S_{11}}-\frac{C_{f}}{C_{p}}
$$


where Gs is the conductance, $\mathrm{Cp}$ is the capacitance of the sample, $\mathrm{C}_{\mathrm{f}}$ is the fringing capacitor, S11 is the reflection coefficient resulting from wave multiple reflection + transmission components in the specimen section.

Short-terminated probes are better suited for thin film specimens. Dielectric materials of precisely known permittivity are often used as a reference for correcting systematic errors due to differences between the measurement and the calibration configurations. The properties of the sample are derived from the reflection due to the impedance discontinuity caused by the sample loading.

(b) Free space

Among the measurement techniques available, the techniques in free space (Varadan et al. 2000; Lamkaouchi et al., 2003) belong to the nondestructive and contactless methods of measurement. They consequently do not need special preparation of the sample; they can be used to measure samples under special conditions, such as high temperature and particularly appropriate to the measurement of non-homogeneous dielectric materials.

With such methods, a sample is placed between 2 antennas: a transmission antenna and a reception antenna placed facing each other and connected to a network analyzer.

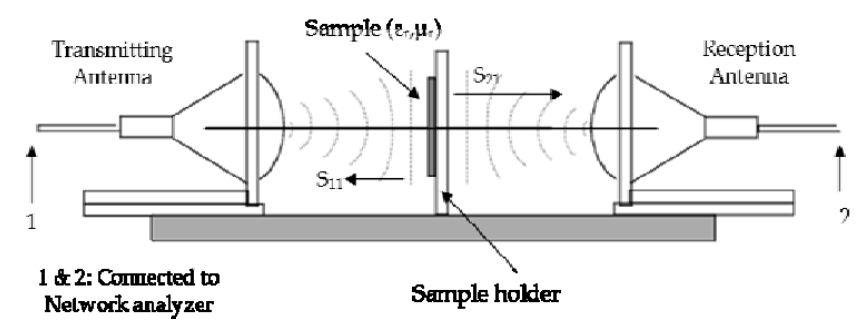

Fig. 2. Free space measurement bench with the sample placed between 2 antennas

Before starting the measurement, the VNA must first be calibrated. Then, using the deembedding function of the VNA, the influence of the sample holder can be cancelled out and only the s-parameter of the MUT can be determined. Time domain gating should also be applied to ensure there are no multiple reflections in the sample itself, though appropriate thickness should able to avoid this. It also eliminates the diffraction of energy from the edge of the antennas. Many conditions s are requirement to obtain perfect results:

- $\quad$ Far field requirements: to ensure that the wave incident to the sample from the antenna can be taken as a plane wave, the distance $d$ between the antenna and the sample should satisfy the following far-field requirement: $d>2 D^{2} / \lambda$, where $\lambda$ is the wavelength of the operating electromagnetic wave and $\mathrm{D}$ is the largest dimension of the antenna aperture. For an antenna with circular aperture, $\mathrm{D}$ is the diameter of the aperture, and for an antenna with rectangular aperture, $\mathrm{D}$ is the diagonal length of the rectangular aperture.

- Sample size: if the sample size is much smaller than the wavelength, the responses of the sample to electromagnetic waves are similar to those of a particle object. To achieve convincing results, the size of the sample should be larger than the wavelength of the electromagnetic wave.

- Measurement environment: An anechoic room is preferable; we can also use timedomain gating to eliminate the unwanted signal caused by environment reflections and multireflections. 
After that, from a precise phase measurement, a precise measurement of the permittivity on a broad frequency band can thus be carried out using generally the "Nicolson-Ross-Weir (NRW) algorithm" (Nicolson \& Ross, 1970; Weir, 1974) where the reflection and transmission are expressed by the scattering parameters S11 and S21 and explicit formulas for the calculation of permittivity and permeability are derived.

\subsection{Thin films measurements}

(a) Short frequency band methods

\section{Capacitive methods:}

The basic methods for measuring the electromagnetic properties of materials at low frequencies consists of placing the material in a measuring cell (capacitor, inductance) where we measure the impedance $Z$ or the admittance $Y=1 / Z$ (Mathai et al, 2002). The permittivity of the material is deduced from the measured value of $\mathrm{Z}$ or $\mathrm{Y}$ using a localized elements equivalent circuit representing the measurement cell. Capacitance techniques (Fig. 3) include sandwiching the thin layer between two electrodes to form a capacitor. They are useful at frequencies extending from fractions of a hertz to megahertz frequencies. Yet, with very small conductors, specimens can be measured up to gigahertz frequencies (Park et al. 2005; Obrzut \& Nozaki, 2001). Capacitance models work well if the wavelength is much longer than the conductor separation. The capacitance for a parallel plate with no fringing fields near the edges and the conductance (represent losses) at low frequency are written as:

$$
C=\frac{\varepsilon^{\prime} \mathrm{A}}{\mathrm{d}} \text { and } \mathrm{G}=\omega \frac{\varepsilon \text { "A }}{\mathrm{d}}
$$

The permittivity can be obtained from measurements of $C$ and $G$ and is given by:

$$
\varepsilon_{\mathrm{r}}=\frac{\mathrm{C}-\mathrm{jG} / \omega}{\mathrm{C}_{\text {air }}-\mathrm{j} \mathrm{G}_{\text {air }} / \omega}
$$

This model assumes no fringing fields. A more accurate model would include the effects of fringing fields. The use of guard electrodes as shown in Fig. 3 minimizes the effects of the fringe field.

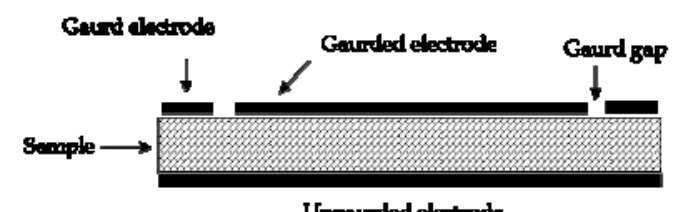

Ungaurded elactrode

Fig. 3. A specimen in a capacitor with electrode guards.

Many procedures of measurement depending on the capacitive techniques have been widely reported during the last decade. These methods whether using transmission lines, interdigital capacitors or the classic capacitor, have their principle basics on measuring the equivalent total impedance of the cell using an impedance analyser where we can measure 
directly the capacitance and conductance or using a network analyser thus measuring the reflection coefficient S11 and deducing the impedance of the whole structure using the formula:

$$
\mathrm{Z}_{\text {in }}=\mathrm{Z}_{0}\left(1+\mathrm{S}_{11}\right) /\left(1-\mathrm{S}_{11}\right)
$$

Then with an analytical work we go up with the dielectric permittivity of the material under test. Other methods use very complicated equivalent circuit to represent the measurement device and increase the accuracy of calculations.

\section{Resonant cavities:}

Resonant measurements are the most accurate methods of obtaining permittivity and permeability. They are widely utilized because of its simplicity, easy data processing, accuracy, and high temperature capabilities. There are many types of resonant techniques available such as reentrant cavities, split cylinder resonators, cavity resonators, fabry-perot resonators etc. This section will concentrate on the general overview of resonant measurements and the general procedure using a cavity resonator.

The most popular resonant cavity method is the perturbation method (PM) (Komarov \& Yakovlev, 2003; Mathew \& Raveendranath, 2001); it is designed in the standard TM (transverse magnetic) or TE (transverse electric) mode of propagation of the electromagnetic fields. It is particularly suited for medium-loss and low-loss materials and substances. Precisely shaped small-sized samples are usually used with this technique. But PM provides dielectric properties measurements only at a resonant frequency, indicated by a sharp increase in the magnitude of the $\left|S_{21}\right|$ parameter. The measurement is based on the shift in resonant frequency and the change in absorption characteristics of a tuned resonant cavity, due to insertion of a sample of target material (Janezic, 2004; Coakley et al. 2003). The specimen is inserted through a clearance hole made at the center of the cavity and that's into region of maximum electric field.

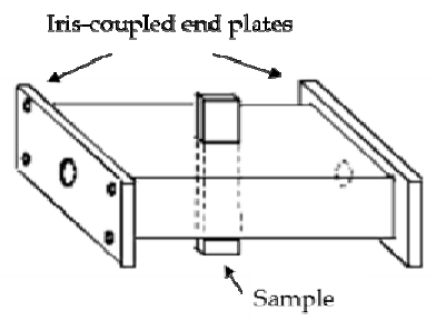

Fig. 4. Resonant cavity with a bar sample inserted at its center.

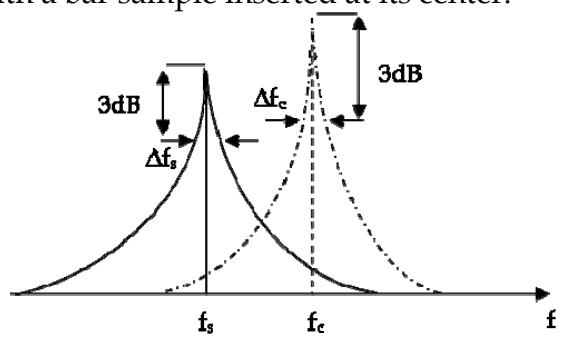

Fig. 5. The resonance response with and without the sample. 
When the dielectric specimen is inserted to the empty (air filled) cavity the resonant frequency decreases from $f_{c}$ to $f_{s}$ while the bandwidth $\Delta f$ at half power, i. e. $3 \mathrm{~dB}$ below the $\left|S_{21}\right|$ peak, increases from $\Delta \mathrm{f}_{\mathrm{c}}$ to $\Delta \mathrm{f}_{\mathrm{s}}$ (see illustration in Fig. 5). A shift in resonant frequency is related to the specimen dielectric constant, while the larger bandwidth corresponds to a smaller quality factor $Q$ (ratio of energy stored to energy dissipated), due to dielectric loss. The cavity perturbation method involves measurements of $\mathrm{f}_{\mathrm{c}}, \Delta \mathrm{f}_{\mathrm{c}}, \mathrm{f}_{\mathrm{s}}, \Delta \mathrm{f}_{\mathrm{s}}$, and volume of the empty cavity $\mathrm{V}_{\mathrm{c}}$ and the specimen volume $\mathrm{V}_{\mathrm{s}}$. The quality factor for the empty cavity and for the cavity filled with the specimen is given by the expressions:

$$
\mathrm{Q}_{\mathrm{c}}=\mathrm{f}_{\mathrm{c}} / \Delta \mathrm{f}_{\mathrm{c}}, \mathrm{Q}_{\mathrm{s}}=\mathrm{f}_{\mathrm{s}} / \Delta \mathrm{f}_{\mathrm{s}}
$$

The real and imaginary parts of the dielectric constant are given by:

$$
\varepsilon_{\mathrm{r}}^{\prime}=1+\frac{\mathrm{V}_{\mathrm{c}}}{2 \mathrm{~V}_{\mathrm{s}}} \frac{\mathrm{f}_{\mathrm{c}}-\mathrm{f}_{\mathrm{s}}}{\mathrm{f}_{\mathrm{s}}}, \varepsilon_{\mathrm{r}}^{\prime \prime}=\frac{\mathrm{V}_{\mathrm{c}}}{4 \mathrm{~V}_{\mathrm{s}}}\left(\frac{1}{\mathrm{Q}_{\mathrm{s}}}-\frac{1}{\mathrm{Q}_{\mathrm{c}}}\right)
$$

As indicated before, this method requires that:

- $\quad$ The specimen volume be small compared to the volume of the whole cavity $\left(\mathrm{V}_{\mathrm{s}}<\right.$ $0.1 \mathrm{~V}_{\mathrm{c}}$ ), which can lead to decreasing accuracy.

- $\quad$ The specimen must be positioned symmetrically in the region of maximum electric field.

However, compared to other resonant test methods, the resonant cavity perturbation method has several advantages such as overall good accuracy, simple calculations and test specimens that are easy to shape.

(b) Large frequency band methods:

\section{Wave guides:}

Two types of hollow metallic waveguides are often used in microwave electronics: rectangular waveguide and circular waveguide. Owing to the possible degenerations in circular waveguides, rectangular waveguides are more widely used, while circular waveguides have advantages in the characterization of chiral materials.

The waveguide usually works at TE10 mode. The width " $a$ " and height " $b$ " of a rectangular waveguide satisfies $b / a=1 / 2$. To ensure the single-mode requirement in materials property characterization, the wavelength should be larger than " $a$ " and less than " $2 a$ ", so that for a given waveguide, there are limits for minimum frequency and maximum frequency. To ensure good propagations, about $10 \%$ of the frequency range next to the minimum and maximum frequency limits is not used. Several bands of waveguides often used in microwave electronics and materials property characterization: $\mathrm{X}, \mathrm{Ka}$ and $\mathrm{Q}$ bands.

The samples for rectangular waveguide method are relatively easy to fabricate, usually rectangular substrates, and films deposited on such substrates.

(Quéffélec et al., 1999; 2000) presented a technique allowing broadband measurement of the permeability tensor components together with the complex permittivity of ferrimagnetics and/or of partly magnetized or saturated composite materials. It is based on the measurement of the distribution parameters, $S_{\mathrm{ij}}$, of a rectangular waveguide whose section is partly filled with the material under test (Fig. 6). The $S_{\mathrm{ij}}$-parameters are measured with a 
vector network analyzer. The sample is rectangular and having the same width of the waveguide, thus to eliminate any existence of air gap.

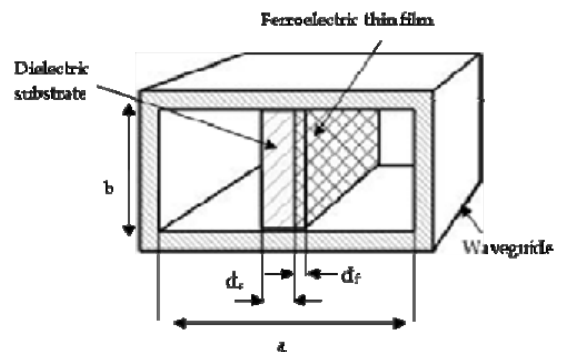

Fig. 6. Rectangular waveguide measurement cell, with a 2-layer sample fitting inside.

The determination of " $\varepsilon$ " and " $\mu$ " of the material from the waveguide $S_{\mathrm{ij}}$ requires to associate an optimization program (inverse problem) to the dynamic electromagnetic analysis of the cell (direct problem). The electromagnetic analysis of the cell is based on the mode-matching method (Esteban \& Rebollar, 1991) applied to the waveguide discontinuities. This method requires the modes determination in the waveguide and the use of the orthogonality conditions between the modes. The main problem in the modal analysis is the calculation of the propagation constant for each mode in the waveguide partly filled with the material; and then to match the modes in the plane of empty-cell/loaded-cell discontinuities. Such an analysis allows a rigorous description of the dynamic behavior of the cell. The electromagnetic analysis approach used is detailed in (Quéffélec et al., 1999).

The complex permittivity and complex components of the permeability tensor are computed from a data-processing program, taking into account higher order modes excited at the cell discontinuities and using a numerical optimization procedure (Quéffélec et al., 2000) to match calculated and measured values of the S-parameters.

Lately the same procedure was used for the measurement of the permittivity of ferroelectric thin film materials deposited on sapphire (Blasi \& Queffelec, 2008) and good results were obtained in the X-band. The goal is to have the less possible error $\mathrm{E}(\mathrm{x})$ for the equation defined by:

$$
\mathrm{E}(\mathrm{x})=\sum \sum\left|S_{\mathrm{ij}}{ }^{\text {th }}(\mathrm{x})-\mathrm{S}_{\mathrm{ij}} \mathrm{mes}(\mathrm{x})\right|^{2}, \text { where } \mathrm{x}=\left(\varepsilon^{\prime}, \varepsilon^{\prime \prime}\right)
$$

Where the indexes 'th' and 'mes' hold for the theoretical and measured parameters.

\section{Transmission lines:}

Transmission-line method (TLM) belongs to a large group of non-resonant methods of measuring complex dielectric permittivity of different materials in a microwave range. They involve placing the material inside a portion of an enclosed transmission line. The line is usually a section of rectangular waveguide or coaxial airline. " $\mathrm{er}$ " and " $\mu \mathrm{r}$ " are computed from the measurement of the reflected signal $\left(S_{11}\right)$ and transmitted signal $\left(S_{21}\right)$. Free-space technique, open-circuit network and the short-circuited network methods are included as a part of this family. But, usually the main types of transmission lines used as the 
measurement cell in TLM are: coaxial line (Vanzura et al. 1994; Shenhui et al., 2003), strip line (Salahun et al. 2001), and the planar circuits: micro-strip line (Queffellec \& Gelin, 1994; Janezic et al. 2003), slot line (planar capacitor) (Petrov et al. 2005), coplanar waveguide (Lue \& Tseng, 2001; Hinojosa et al., 2002) and inter-digital capacitors (Su et al., 2000; Al-Shareef et al. 1997).

Coaxial line: Due to their relative simplicity, coaxial line transmission or reflection methods are widely used broadband measurement techniques. In these methods, a precisely machined specimen (Fig. 7Error! Reference source not found.) is placed in a section of coaxial line totally filling this section, and the scattering parameters are measured. The relevant scattering equations relate the measured scattering parameters to the permittivity and permeability of the material.

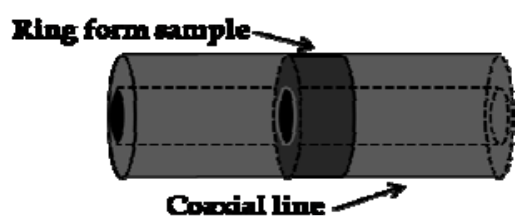

Fig. 7. Coaxial structure with the material to be tested filling completely a section part.

For TEM mode, the complex relative permeability and permittivity can be found as (Shenhui et al., 2003):

$$
\varepsilon_{\mathrm{r}}=\mathrm{Z}_{0} \gamma \lambda / \mathrm{j} \mathrm{Z}_{\mathrm{s}} 2 \pi, \mu_{\mathrm{r}}=\mathrm{Z}_{\mathrm{s}} \gamma \lambda / \mathrm{j} \mathrm{Z}_{0} 2 \pi
$$

Where $\mathrm{Zs}$ is the characteristic impedance of the sample, Z0 is the characteristic impedance of the air for the same dimensions, $\lambda$ is the free space wavelength and $\gamma$ is the propagation constant written in terms of S-parameters as follows:

$$
\gamma \mathrm{l}=\cosh ^{-1}\left(\left(1-\mathrm{S}_{11^{2}}+\mathrm{S}_{21}{ }^{2}\right) / 2 \mathrm{~S}_{21}\right)
$$

And " 1 " is the sample thickness.

Corrections for the effects of air gaps between the specimen holder and the sample can be made by analytical formulas (Vanzura et al., 1994). For coaxial lines, an annular sample needs to be fabricated. The thickness of the sample should be approximately one-quarter of the wavelength of the energy that has penetrated the sample. Although this method is more accurate and sensitive than the more recent coaxial probe method, it has a narrower range of frequencies. As the substance must fill the cross-section of the coaxial transmission line, sample preparation is also more difficult and time consuming.

Strip line: This method (Salahun et al., 2001) allows a broad-band measurement of the complex permittivity and permeability of solid and isotropic materials. The samples to be tested are either rectangular plates or thin films put (or mounted) on a dielectric holder. This method is based on the determination of the distribution parameters, $S_{i j}$, of a 3-plate transmission microstrip line that contains the material to be tested (Fig. 8). 


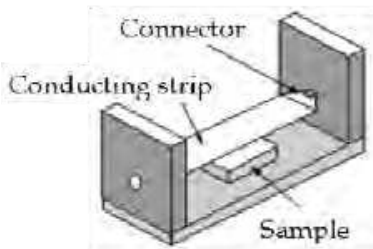

Fig. 8. Strip line measuring cell: Schematic drawing of an asymmetrical stripline structure. The sample is laid on the ground plane (Source: Salahun et al. 2001).

The method presents 3 steps: firstly, the theoretical effective permittivity and effective permeability are calculated from:

$$
\varepsilon_{\mathrm{eff}}^{\mathrm{th}}=\mathrm{C} / \mathrm{C}_{0} \text { and } \mu_{\mathrm{eff}}^{\mathrm{th}}=\mathrm{L} / \mathrm{L}_{0}
$$

Where $(\mathrm{L}, \mathrm{C})$ and $\left(\mathrm{L}_{0}, \mathrm{C}_{0}\right)$ are the inductance and capacitance per unit of length calculated in the cell with and without the sample. In the 2nd step, supposing a TEM mode in the cell, the effective permittivity and permeability are calculated using the Nicolson/Ross procedure mentioned in the free space method previously. In the last step, the complex electromagnetic parameters of the material are calculated by matching theoretical and measured effective values. Errors equations for the complex permeability and permittivity of the material are solved using a dichotomous procedure in the complex plane.

$$
\left\{\begin{array}{l}
F\left(\mu^{\prime}, \mu^{\prime \prime}\right)=\left|\mu_{\text {eff }}^{\mathrm{m}}-\mu_{\text {eff }}^{\text {th }}\right|^{2} \\
G\left(\varepsilon^{\prime}, \varepsilon^{\prime \prime}\right)=\left|\varepsilon_{\text {eff }}^{\mathrm{m}}-\varepsilon_{\text {eff }}^{\text {th }}\right|^{2}
\end{array}\right.
$$

The method enables one to get rid of sample machining problems (presented in the previous coaxial line methods) since the latter does not fully fill in the cross-section of the cell.

Micro-strip line: Microstrips have long been used as microwave components, and show many properties which overcome some of the limitations of non-planar components, thus making it suitable for use in dielectric permittivity measurement. These methods can be destructive and non-destructive. A destructive technique in presented by (Janezic et al., 2003), where the thin film is incorporated in the microstrip line. The advantage of this technique is the ability to separate the electrical properties of the metal conductors from the electrical properties of the thin film by separate measurements of the propagation constant and the characteristic impedance of the microstrip line. From the propagation constant and characteristic impedance, the measured distributed capacitance and conductance of the microstrip line are determined. Then knowing the physical dimensions of the microstrip lines, the thin-film permittivity is related to the measured capacitance by using a finitedifference solver. Yet precise, a more advantageous method is a non-destructive where the material to be measured is left intact for later integration in applications. A method of this type is published in the work of (Queffellec \& Gelin, 1994) where the material to be measured is placed on the microstrip line. And as, it is well known that the effective permittivity (a combination of the substrate permittivity and the permittivity of the material above the line) of a microstrip transmission line (at least for thin width-to-height ratios) is 
strongly dependent on the permittivity of the region above the line, this effect has been utilized in implementing microwave circuits and to a lesser extent investigation of dielectric permittivity.

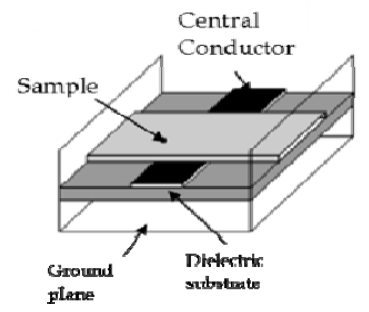

Fig. 9. Microstrip device loaded with the sample (Source: Queffelec et al. 1998).

This method (Fig. 9) allows a broad-band measurement of the complex permittivity and permeability of solid and isotropic materials. The samples to be tested are either rectangular plates or thin films. This method is based on the determination of the distribution parameters, $S_{i j}$, of a microstrip line that contains the material to be tested. The method is original because the sample is directly placed onto the line substrate without needing to fully fill in the cross-section of the cell as in the case of waveguides and coaxial cables. The analysis of measured data, that is, the determination of complex " $\varepsilon$ " and " $\mu$ " from $S_{i j}$ requires associating an optimization program (inverse problem) to the electromagnetic analysis of the cell (direct problem) as follows:

- $\quad$ The spectral domain approach was used in the direct problem, allows one to take into account several propagation modes in the calculation. and later in (Queffelec et al., 1998) the mode matching method.

- $\quad$ The inverse problem is solved using a numerical optimization process based on the Raphson-Newton method and the results for the permittivity and permeability were obtained on a large frequency band up to $18 \mathrm{GHz}$.

Slot line (Planar capacitor): One of the simplest devices for evaluating the electrical properties of ferroelectric materials is the capacitor. There are two types: parallel plate capacitors discussed above, where the ferroelectric layer is sandwiched between the electrodes; and planar capacitors, where the electrodes are patterned on the same side of a ferroelectric film and are separated by a small gap (Petrov et al., 2005).

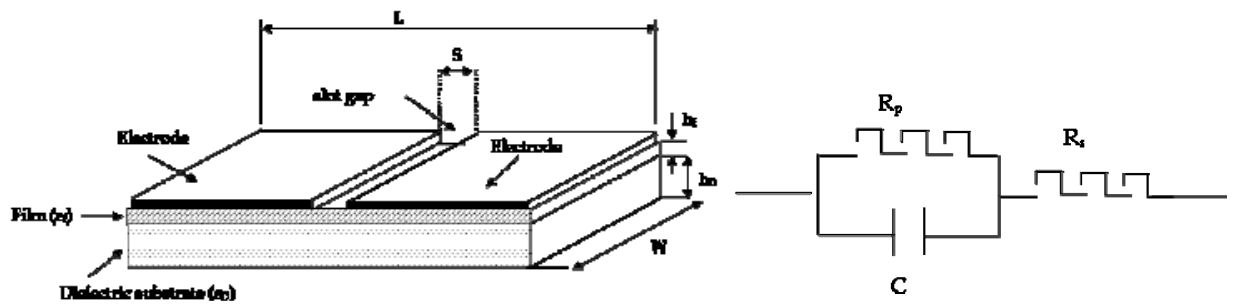

Fig. 10. Planar capacitor structure and its equivalent circuit (Rs and $\mathrm{Rp}$ are the series and parallel resistors representing loss). 
Fig. 10 shows the planar capacitor device used for measurement of the dielectric permittivity of the ferroelectric thin film incorporated in the structure (destructive) and its equivalent circuit model used to go up with the total impedance of the structure through measuring the reflection coefficient S11 and then the impedance using equation (6). And the permittivity of the thin film is written as follows:

$$
\varepsilon_{\mathrm{F}}=\left[\frac{\mathrm{C}}{\mathrm{w} \varepsilon_{0}}-\frac{2}{\pi} \ln \left(4 \frac{1}{\mathrm{~s}}\right)-\frac{\left(\varepsilon_{\mathrm{D}}-1\right)}{\pi} \ln \left(16 \frac{\left(\mathrm{h}_{\mathrm{D}}+\mathrm{h}_{\mathrm{F}}\right)}{\pi \mathrm{s}}\right)\right] \times\left[\frac{\mathrm{s}}{\mathrm{h}_{\mathrm{F}}}+\frac{4}{\pi} \ln (2)\right]+\varepsilon_{\mathrm{D}}
$$

Where, $C$ is the capacitance of the structure, $h_{F}$ is the ferroelectric film thickness; $h_{D}$ is the substrate thickness, $\mathrm{s}$

is the gap width, 1 is the electrode length, $w$ is the electrode width and $\varepsilon_{D}$ is the dielectric constant of the substrate. It should be noted that equation (26) is valid under the following limitations: $\varepsilon_{\mathrm{F}} / \varepsilon_{\mathrm{D}} \geq 10^{2}$,

$\mathrm{h}_{\mathrm{F}}<\mathrm{s}<10 \mathrm{~h}_{\mathrm{F}}, \mathrm{s}<0.251$ and $\mathrm{s}<0.5 \mathrm{hD}$. Using this approach, the dielectric permittivity of the STO film was evaluated to be about $\varepsilon^{\prime} \sim 3500$ at $77 \mathrm{~K}, 6 \mathrm{GHz}$.

Coplanar lines: The coplanar lines were the subject of increasing interest during the last decade in that they present a solution at the technical problems, encountered in the design of the strip and micro-strip standard transmission lines (their adaptation to the external circuits is easier and their use offers relatively low dispersion at high frequencies).

Many characterization methods using coplanar lines are published. (Hinojosa, et al. 2002) presented an easy, fast, destructive and very high broadband $(0.05-110 \mathrm{GHz})$ electromagnetic characterization method using a coplanar line as a cell measurement to measure the permittivity of a dielectric material on which the line is directly printed (Fig. 11). The direct problem consists of computing the S-parameters at the access planes of the coplanar cell under test propagating only the quasi-TEM mode. The optimization procedure (the inverse problem) is based on an iterative method derived from the gradient method (Hinojosa et al., 2001), simultaneously carrying out the ' $\varepsilon_{\mathrm{r}}$ ' and ' $\mu_{\mathrm{r}}$ ' computation and the convergence between $\left(S_{11}, S_{21}\right)$ measured values and those computed by the direct problem through successive increment of the permittivity and permeability values.

Another method is presented by (Lue \& Tseng, 2001). A technique using a coplanar waveguide incorporating the ferroelectric thin film deposited on a dielectric substrate.

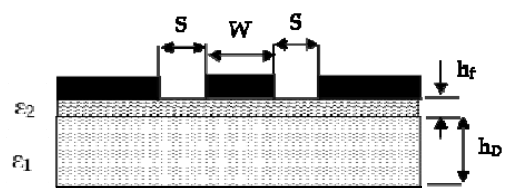

Fig. 11. Coplanar line incorporating the thin ferroelectric film.

It is based on an easy and fast processing method of the coplanar S-parameter measurements, which takes into account the quasi-TEM mode propagation. Analytical relationships compute the propagation constant and characteristic impedance of the coplanar cell instead of any numerical method, which considerably decreases computation time, and the effective permittivity of the multi-layered structure is deduced. The S- 
parameter measurement bench of the coplanar cells employs vector network analyzers and commercially available high-quality on-coplanar test fixtures (probe station). The extraction of the permittivity of the thin film is done using the conformal mapping analysis.

Coplanar interdigital capacitor:

Another type of characterization methods which use the coplanar wave guide structure are those of the coplanar interdigital capacitor. These methods have the strip line or the central conductor in the form of interdigitated fingers (Fig. 12) in a way to increase the electromagnetic interaction between the propagating wave and the sample, thus increasing the sensitivity of the structure.
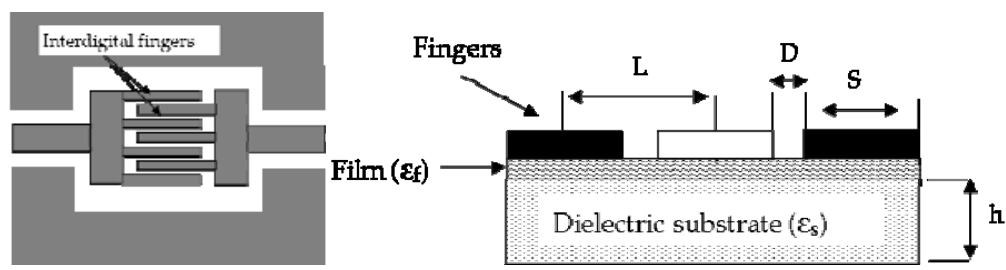

Fig. 12. coplanar IDC (left) with fingers parallel to the wave propagation with a schematic of a cross section of the capacitor structure (right).

As reported by (Al-Shareef et al., 1997); to calculate the dielectric constant of the thin film capacitors with the interdigital electrode configuration shown in Fig. 12, an analytical model previously derived by Farnell et al. was employed (Farnell et al., 1970). Based on Farnell's analysis, it can be shown that the dielectric constant of a thin film having the configuration shown in Fig. 1 can be calculated using the following expression:

$$
\varepsilon_{\mathrm{f}}=\varepsilon_{\mathrm{s}}+\left\{\left[\mathrm{C}-\mathrm{K}\left(1+\varepsilon_{\mathrm{s}}\right)\right] /(\mathrm{K}[1-\exp (-4.6 \mathrm{~h} / \mathrm{L})])\right\}
$$

where ef and es are the film and substrate dielectric constants, respectively; $h$ is the film thickness, $\mathrm{K}$ is a constant which has units of $\mathrm{pF}$, and $\mathrm{C}$ is the measured capacitance per unit finger length per electrode section of width $L$ ( $L$ is half the IDE pattern period or $l=2$ ).

Another procedure for low frequency measurement is to measure directly the impedance using an impedance analyzer (1 layer material case), or using the conformal mapping method to calculate analytically, the capacitance of the structure and compare this latter to the measured value thus deducing the permittivity of the material under test.

\section{Non-destructive transmission line method: Characterization using a Coplanar line}

Principles and techniques of permittivity measurements using transmission lines have been illustrated in the preceding part. Yet, most of these methods have the thin film incorporated inside the device (Lue \& Tseng, 2001) (a destructive method), which prevent using the measured film material in an electronic circuit. And as ferroelectric film deposition and permittivity values still not well controlled, this poses a problem in their integration. 
Therefore, a non-destructive method will be the most appropriate for such situation as well as for industrial use in general.

We present here a nouvelle and non-destructive Broadband characterization method which employs a coplanar line for the measurement of the complex permittivity of linear dielectric materials and precisely, that of ferroelectric thin films. The method uses the transmission coefficient supposing a quasi-TEM analysis to find the effective permittivity of the multilayer system. In the inverse problem, the coplanar conformal mapping technique is employed to extract the relative permittivity of the thin layer.

\subsection{Theory and analysis}

The theory of the method and its principle is very simple; the substrate to be measured is placed on the line for an assembly as described in Fig. 13 below, where the line is taken in sandwich between 2 dielectric substrates, that of the line and the material to measure.

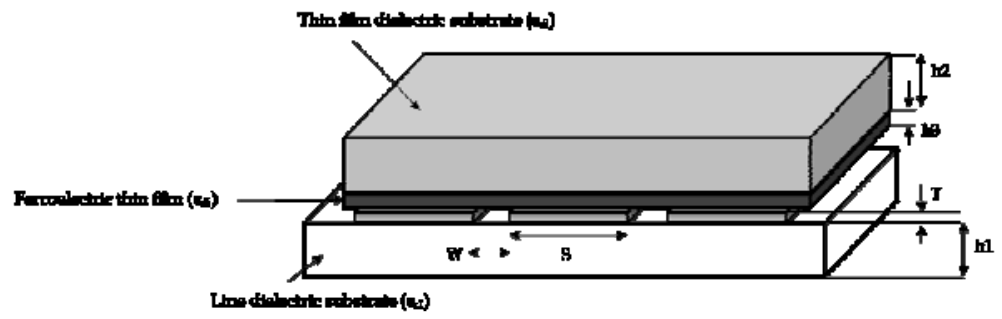

Fig. 13. Schematic of a CPW tight between two dielectrics: Alumina substrate from below and the ferroelectric thin film $+\mathrm{MgO}$ substrate from above.

The method includes measuring 'only' the transmission coefficient $S_{21}$ of the device and that's in two steps: - the first for the coplanar line in air (without material), - and the other with the line loaded with material whether of one layer or multi-layers.

The effects of the different materials on the dispersion parameters of the line results of these measurements are presented in Fig. 14.

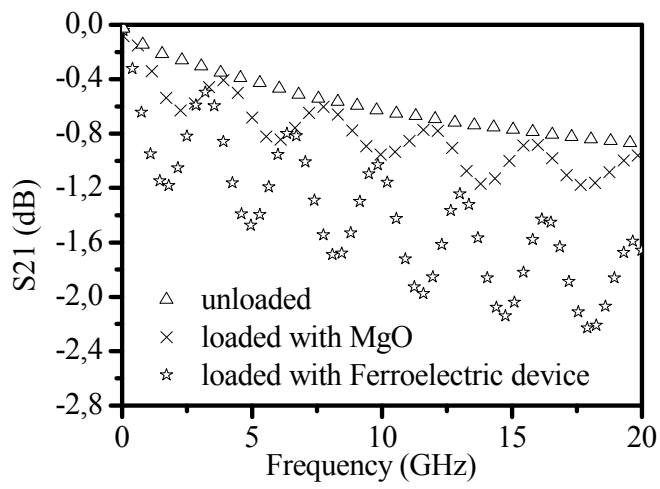

Fig. 14. S-parameters measured with 3 different samples placed on the coplanar line: unloaded (air), $\mathrm{MgO}$ substrate and 2-layered device: $\mathrm{MgO}+$ ferroelectric thin film 
The measurement procedure is presented in 2 problems: a direct one and an inverse one.

\subsection{Analysis of the direct problem}

The analysis is based on the measurements of the S-parameters of the line and precisely the transmission coefficient $S_{21}$. We have for a standard transmission line the S-parameters written as follows:

$$
S_{i j}=\left[\begin{array}{cc}
0 & e^{-\phi} \\
e^{-\phi} & 0
\end{array}\right]
$$

Where $\mathrm{L}$ is the line length, and $\phi=\gamma l$ is the $S_{21}$ phase shift. The propagation constant of a coplanar wave guide is well known to be:

$$
\gamma=\mathrm{j} \frac{2 \pi}{\mathrm{c}} \mathrm{f} \sqrt{\varepsilon_{\text {eff }} \mu_{\text {eff }}}
$$

The ratio of the two measurements mentioned gives the following formula:

$$
\stackrel{\text { (loaded) }}{\mathrm{S}_{21}} / \underset{\text { (unloaded) }}{\mathrm{S}_{21}}=\mathrm{e}^{-\left(\gamma_{\mathrm{c}}-\gamma_{\mathrm{v}}\right)}=\mathrm{e}^{\mathrm{j} \frac{2 \pi}{\mathrm{c}} \cdot \mathrm{f} \cdot \mathrm{l} \cdot\left(\sqrt{\varepsilon_{\text {reff }}}-\sqrt{\varepsilon_{\text {reff }}}\right)}
$$

Where $\left(\gamma_{c}\right)$ and $\left(\gamma_{v}\right)$ are propagation constant of the system with and without the load respectively, $\varepsilon_{\text {eff }}$ is the effective permittivity of the whole system, $\mu_{\text {eff }}$ the effective permeability which is equal to ' 1 ' in the case of dielectric medium and ' $f$ ' is the frequency. This equation makes it possible to extract the effective permittivity of the complete system (line + DUT) that we will note " $\varepsilon_{\mathrm{effc}}$ ".

\subsection{Quasi-TEM analysis and Inverse problem}

From the previous analysis, we extracted the effective permittivity of the complete system (coplanar line+ coplanar substrate + the material to be measured (1-layer or 2-layers)). In this section, the conformal mapping analysis is carried out to solve the inverse problem. The conformal mapping technique assumes a quasi-static TEM mode of propagation along the line. Closed form expressions for the effective permittivity and the characteristic impedance for CPW are presented in (Simons, 2001). The simplified formulas for the sandwiched 3layered CPW structure are given here; where we have the effective permittivity written as follows:

$$
\varepsilon_{\mathrm{eff}}=1+\mathrm{q}_{1}\left(\varepsilon_{\mathrm{r} 1}-1\right)+\mathrm{q}_{2}\left(\varepsilon_{\mathrm{r} 2}-1\right)+\mathrm{q}_{3}\left(\varepsilon_{\mathrm{r} 3}-\varepsilon_{\mathrm{r} 2}\right)
$$

With $\varepsilon r 1$ is the dielectric constant of the line substrate, $\varepsilon r 2$ is that of the thin film substrate (the substrate on which the film is deposited), $\varepsilon r 3$ is the permittivity of the thin film and qi is the partial filling factor equal to: 


$$
\mathrm{q}_{\mathrm{i}}=\frac{1}{2} \frac{\mathrm{K}\left(\mathrm{k}_{\mathrm{i}}\right)}{\mathrm{K}^{\prime}\left(\mathrm{k}_{\mathrm{i}}\right)} \frac{\mathrm{K}^{\prime}\left(\mathrm{k}_{0}\right)}{\mathrm{K}\left(\mathrm{k}_{0}\right)}, \mathrm{i}=1,2,3, \ldots
$$

$K(x)$ is the complete elliptical integral of first kind, and $K^{\prime}(x)=K\left(\sqrt{1-x^{2}}\right)$ and their modulus $\mathrm{k}_{0}$ and $\mathrm{k}_{\mathrm{i}}$ are written:

$$
\mathrm{k}_{0}=\mathrm{s} /(\mathrm{s}+2 \mathrm{w}), \mathrm{k}_{\mathrm{i}}=\sinh \left(\pi \mathrm{s} / 4 \mathrm{~h}_{\mathrm{i}}\right) / \sinh \left(\pi(\mathrm{s}+2 \mathrm{w}) / 4 \mathrm{~h}_{\mathrm{i}}\right)
$$

$\mathrm{s}$ and $\mathrm{w}$ are the CPW conductor and slot width respectively, $\mathrm{h}_{\mathrm{i}}$ is the thickness of the 3 different layers.

To simplify our calculations usually we employ the asymptotic formula for the ratio of elliptic function and that under the following conditions:

For

$$
0 \leq \mathrm{k}_{\mathrm{i}} \leq 0.707 \Rightarrow \frac{\mathrm{K}\left(\mathrm{k}_{\mathrm{i}}\right)}{\mathrm{K}^{\prime}(\mathrm{ki})}=\pi / \ln \left(\frac{2\left(1+\sqrt{\mathrm{J}_{\mathrm{i}}}\right)}{1-\sqrt{\mathrm{J}_{\mathrm{i}}}}\right) \text { where } \mathrm{J}_{\mathrm{i}}=\sqrt{1-\mathrm{k}_{\mathrm{i}}}
$$

and for

$$
\mathrm{k}_{\mathrm{i}} \geq 0.707 \Rightarrow \frac{\mathrm{K}\left(\mathrm{k}_{\mathrm{i}}\right)}{\mathrm{K}^{\prime}\left(\mathrm{k}_{\mathrm{i}}\right)}=\ln \left(\frac{2\left(1+\sqrt{\mathrm{k}_{\mathrm{i}}}\right)}{1-\sqrt{\mathrm{k}_{\mathrm{i}}}}\right) / \pi
$$

For a thickness $h_{i}$ too small compared to the line parameters, that is, if $s, w>>h_{3}$ (which is the case), $\mathrm{k}_{3}$ become too small $\left(\mathrm{k}_{3}<<<1\right)$, which leads to a numerical error in calculating the elliptic function. To overcome this difficulty, for the special case (Zhao, 2005) when $\mathrm{k}_{\mathrm{i}} \approx 0$;

$$
\frac{\mathrm{K}\left(\mathrm{k}_{\mathrm{i}}\right)}{\mathrm{K}^{\prime}\left(\mathrm{k}_{\mathrm{i}}\right)}=\pi / \ln \left(2 \frac{1+\sqrt{\sqrt{1-\mathrm{k}_{\mathrm{i}}}}}{1-\sqrt{\sqrt{1-\mathrm{k}_{\mathrm{i}}}}}\right) \approx \pi / \ln \frac{16}{\mathrm{k}_{\mathrm{i}}^{2}}
$$

The resolution of the inverse problem is carried out by applying these formulas which makes it possible to determine the permittivity of material. In the quasi-TEM case, these simplified expressions for a tri-layer structure make it possible to extract the complex permittivity of the thin layer ' $\varepsilon_{\mathrm{r} 3}$ ' from the following equation:

$$
\varepsilon_{\mathrm{r} 3}=\frac{\varepsilon_{\mathrm{eff}}-1-\mathrm{q}_{1}\left(\varepsilon_{\mathrm{r} 1}-1\right)+\mathrm{q}_{2}\left(\varepsilon_{\mathrm{r} 2}-1\right)}{\mathrm{q}_{3}}+\varepsilon_{\mathrm{r} 2}
$$

\subsection{Numerical Calculation (FEM, TLM)}

An analysis based on the conformal mapping method was done using a Matlab program. With this program we studied the effect of the material placed on the line on the effective permittivity of the system (Figure 15): 


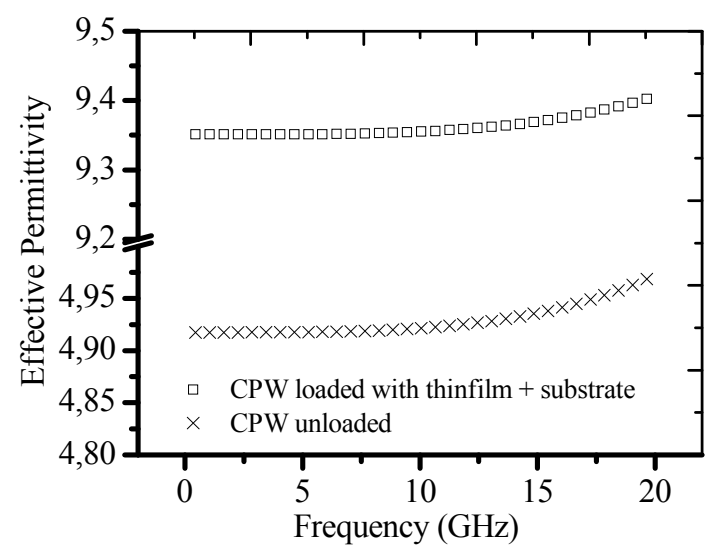

Fig. 15. Results for the effective permittivity calculated for the coplanar line when unloaded and loaded with the thin film device (thin film + substrate) where the substrate is $\mathrm{MgO}$ of permittivity 9.5 and the permittivity of the thin film considered 200 with a thickness of $500 \mu \mathrm{m}$ for the substrate and $0.5 \mu \mathrm{m}$ for the thin layer.

As shown in the figure, the effect is far being negligible. This result shows the high sensitivity of the coplanar device and the reliability of the method used in the calculations. The simulation with 3D electromagnetic commercial softwares gave comparable results.

\subsection{Measurement bench}

(a) Optimization of the coplanar device

A number of simulations are done using 3D electromagnetic simulation softwares in a way to optimize the coplanar device and the measurement method in general, and permittivity extractions took place with different line parameters employed as well.

The coplanar line employed here, was designed for a characteristic impedance of $50 \Omega$ to match the coaxial cable of the network analyser used to measure the S-parameters. Alumina was taken as the device support substrate of permittivity 9.8 and different dimensions. The parameters for the coplanar printed on the substrate are as follows: Substrate thickness = $0.635 \mathrm{~mm}$, central conductor width $\mathrm{w}=380 \mu \mathrm{m}$, spacing between the central conductor and the ground plane $\mathrm{s}=150 \mu \mathrm{m}$ with a metallic thickness $\mathrm{t}=2 \mu \mathrm{m}$.

(b) Measurements procedure

The measured samples are best to be rectangular yet, any form with known length with paralleled surfaces can be measured. The materials must have smaller length than the line but wider enough to cover the 2 ground planes in a way to confine the most possible field lines. The material to be measured is simply placed on the line; for a thin film deposited on a dielectric substrate and considering a higher permittivity for that film compared to its substrate $\left(\varepsilon_{\mathrm{r} 3}>10 . \varepsilon_{\mathrm{r} 2}\right)$, this device should be placed on the film side for the conformal mapping analysis to be valid. That is, going from the metallic line, the permittivity of the different layers should decrease on the 2 sides. The thin ferroelectric films measured here are barium strontium titanate (BST) deposited by RF-sputtering with thicknesses varied 
between $0.5 \mu \mathrm{m}$ and $1 \mu \mathrm{m}$ on $\mathrm{MgO}$ and sapphire substrates. The S-parameters are measured using a vector network analyzer HP $8510 \mathrm{C}$ functioning to a frequency of $20 \mathrm{GHZ}$. The line is mounted on a classical ANRITSU test-fixture. Both transmission coefficients measured in air and with material are integrated in a MATLAB program in order to extract the permittivity of the ferroelectric thin layer by applying the analysis described above.

TRL (Thru-Reflect-Line) and SOLT (Short-Open-Load-Thru) calibrations were carried out in order to eliminate systematic errors of the network analyzer and to place the reference planes of measurements at the needed positions, i.e.: at the levels the 2 coaxial cable for the SOLT and at the sample edges for the TRL case. The disadvantage of the TRL calibration is the necessity to have different line kits in order to measure different sample lengths. For the SOLT case, the reference planes are always at the CPW line edges and whatever sample can be measured, yet, because of the distance between the line edge and that of the sample, reflections take place causing a number of oscillations in the measured results all over the frequency band (Fig. 14). Solution for this problem is discussed in (Kassem et al., 2007).

\subsection{Experimental results and discussion}

To validate our method, we characterized several materials with well known dielectric properties (alumina, $\mathrm{MgO}$, Sapphire...). The results obtained for $\mathrm{MgO}$ of rectangular shape (13x13) $\mathrm{mm}^{2}$ surface and $0.5 \mathrm{~mm}$ thickness, as for other materials, show a good agreement with the awaited values. The result for the $\mathrm{MgO}$ substrate is presented in Fig. 16. which shows a number of oscillations over the whole frequency band with a mean of around 9.4 for the permittivity value and a fraction of $<10^{-3}$ for this low-loss substrate.

Concerning the ferroelectric thin film measurement, the thin layer deposited on the $\mathrm{MgO}$ substrate was measured by the same way like the $\mathrm{MgO}$ substrate and the results presented below in figure 17 also shows oscillations over the entire frequency band but with a mean value of around 62 for its relative permittivity.

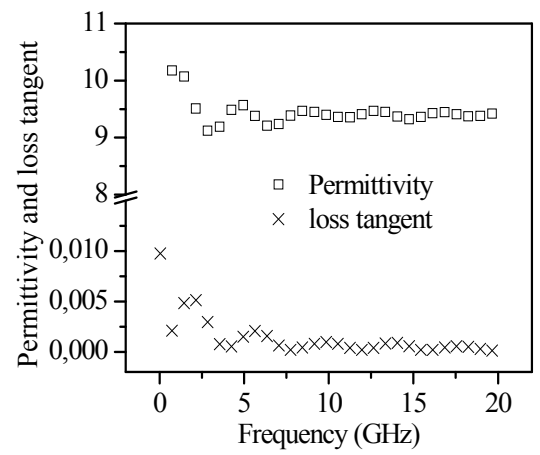

Fig. 16. permittivity and loss tangent measured for $\mathrm{MgO}$. 


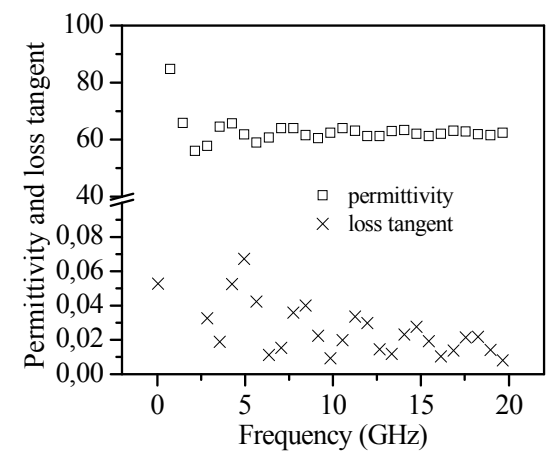

Fig. 17. permittivity and loss tangent measured for ferroelectric thin film layer.

The main reason behind the oscillations figured above is the calibration procedure followed before measurement. In fact, as we mentioned before, the SOLT calibration moves the reference planes to the side edges of the coplanar line, thus, for a sample less in dimension than that of the line, our device can be figured as a 3 regions structure (Fig. 18-left).

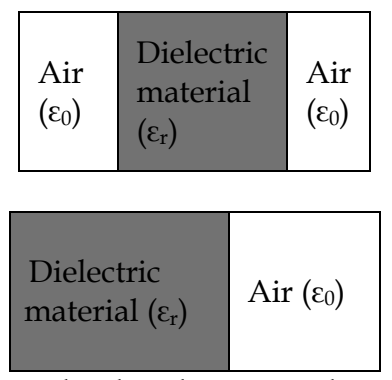

Fig. 18. coplanar line with the sample placed on it, in the 2 cases of: (left) 3 region systems (air, material, and then air), (right) 2 region system (air, material).

So, the EM wave will propagate in different regions each of different permittivity (Air/DUT/Air), thus reflections at the interfaces, which is not taken in our calculations. In a way to minimize this effect, we placed the sample at one edge of the line to have almost a 2 regions structure (Fig. 18-right). Oscillations are largely minimized over the entire frequency band after this procedure. TRL calibration can solve easily this problem.

\subsection{Error analysis, losses and measurement limitation}

The precision of the measurement method is limited by the percentage of errors and losses (Raj et al., 2001, kassem et al., 2007) and by the band of validity of the analysis used.

One of the major limitation of this method, and in general, for any non-destructive method is the presence of an air gap between the DUT and the metallic strips (Fig. 19) which in case of existence can lead to large uncertainties in the values of the permittivity measurement and result. This can be well noticed in 
Fig. 20, which describes the effect of the presence of an air gap on the results of the permittivity of an alumina substrate.

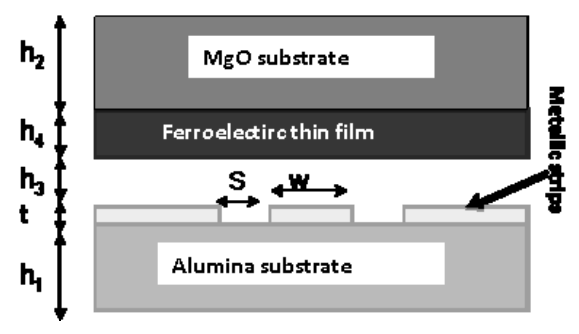

Fig. 19. Cut view of a multilayered coplanar waveguide monitoring the air-gap $h_{3}$.

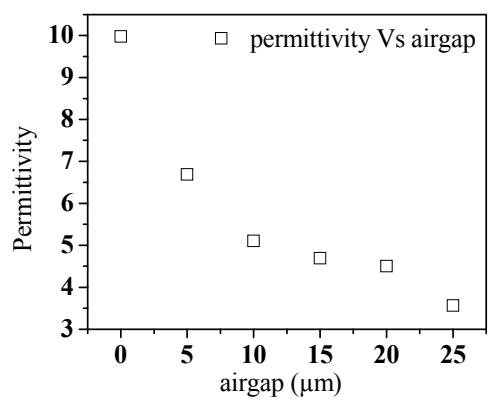

Fig. 20. variation of permittivity of alumina sample for different air gap thicknesses.

As it can be noticed from the graph, the error is more than $50 \%$ for a $20 \mu \mathrm{m}$ air-gap. Although, in our measurement, the metallic strips were well polished thus having a good contact, the effect of the air gap can be taken into consideration introducing a small factor $\mathrm{q}_{3}\left(\varepsilon_{\mathrm{r} 3}-\varepsilon_{\mathrm{r} 4}\right)$ which takes in account the thickness of the existent air-gap $\mathrm{h}_{3}$ (M. Misra1 et al., 2003), thus we have the effective permittivity of the multilayered system with the airgap written as follows:

$$
\varepsilon_{\text {eff }}=1+\mathrm{q}_{1}\left(\varepsilon_{\mathrm{r} 1}-1\right)+\mathrm{q}_{2}\left(\varepsilon_{\mathrm{r} 2}-1\right)+\mathrm{q}_{3}\left(\varepsilon_{\mathrm{r} 3}-\varepsilon_{\mathrm{r} 4}\right)+\mathrm{q}_{4}\left(\varepsilon_{\mathrm{r} 4}-\varepsilon_{\mathrm{r} 2}\right)
$$

And then inversing the problem will give us the effective permittivity of the thin ferroelectric film material:

$$
\varepsilon_{\mathrm{r} 4}=\left[\varepsilon_{\mathrm{eff}}-1-\mathrm{q}_{1}\left(\varepsilon_{\mathrm{r} 1}-1\right)-\mathrm{q}_{2}\left(\varepsilon_{\mathrm{r} 2}-1\right)-\mathrm{q}_{3}\left(\varepsilon_{\mathrm{r} 3}\right)+\mathrm{q}_{4}\left(\varepsilon_{\mathrm{r} 2}\right)\right] /\left(\mathrm{q}_{4}-\mathrm{q}_{3}\right)
$$

(a) Substrate Roughness (presentation of the problem):

Yet, for us, an air gap exists only if one forces the existence of such a layer. The fact is that, we'll always have a contact established between the substrate and the line; our problem here really relates the percentage of surface roughness of the substrate or thin layer. Fig. 21 gives an idea of the situation: 

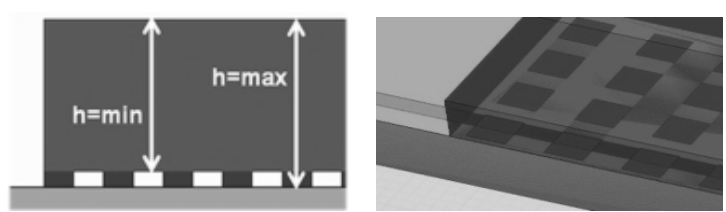

Fig. 21. Layer with a rough surface: (left) peaks, (right) holes, Substrate roughness $(\%)=$ $\mathrm{h}_{\max }-\mathrm{h}_{\min } / \mathrm{h}_{\max } .100$.

One can imagine two types of problems, that is to say a layer with holes, or peaks. We simulated these two conditions with HFSS, for a 2-layers and 3-layers system, then using our program we calculated the permittivity of substrate and the film, and here are the obtained results for the thin film (Fig. 22).
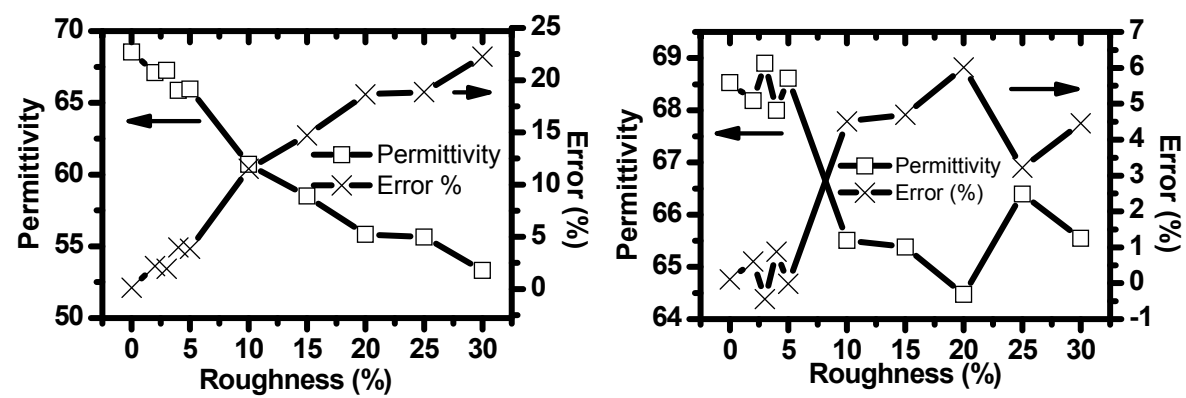

Fig. 22. Simulation made for Double-layered MgO + BST of permittivity 69 and a surface with peaks and 2 solutions proposed to solve the problem (left) calculating with a maximum thickness for the thin layer and (right) a minimum thickness.

Calculations of the permittivity of the film are done using the following 2 different procedures:

- Considering that the thickness of the film is maximal " $\mathrm{h}_{\max }$ ".

- Calculating with the minimal thickness " $\mathrm{h}_{\min }$ "

The calculation with minimal thickness reduces the error to $5 \%$ maximum for $30 \%$ film roughness and even for $10 \%$ roughness; the error in the permittivity value will not bypass the $3 \%$. In conclusion, all depends on the substrate of the layer. For that, a solution is proposed and validated.

\section{Conclusion and Future Research}

The objective of the work is to point on an important part in nowadays electronic domain and that is, the characterization of materials; a necessary process before integrating them in electronic devices such as, tunable filters and tunable phase shifters. Our work concern studying the electrical properties of dielectrics and precisely those of thin ferroelectric materials and that, on a broad frequency band in a first step before their dynamic behavior study (response under application of external electric field). Thus, we can contribute in the realization of tunable circuits at high frequencies starting from such layers. 
In the first part, we presented various methods of characterization allowing measuring the dielectric properties of dielectric materials. The method were divided in a way that allows us to choose what tool of characterization is the most appropriate for each case, moreover, we put the light on the aspect of thin films characterizations which is not yet commercialized and always in the period of its development.

The broad band method proposed makes it possible to calculate the electric parameters of films of high permittivity mounted in a multi-layered device, on a coplanar line structure. The method presents an originality compared to normally used transmission lines methods and that in its nondestructive way of measurement, thus presenting an industrial advantage. Starting from the measurement of the propagation constant from the transmission coefficient of the S-parameters, an approach based on the method of Conformal Mapping is utilized to solve the inverse problem and thus, namely to determine the complex permittivity of a thin layer. The method was validated via the measurements made on various dielectric substrates such as alumina and $\mathrm{MgO}$ and of various thicknesses. The extraction of the dielectric properties of these substrates made it possible to include/understand well the process of measurement to follow. A rather good precision was reached for the permittivity like for the tangent of losses due to the advantage of using a differential measurement, thus eliminating various types of losses automatically. A satisfactory comparison of the results obtained on a layer of $\mathrm{MgO}$ and multi-layer BST/MgO was carried out between our broad band method and a cavity resonator method. After that, a study of the effect of air gap and material surface roughness is done giving larger understands of the measurement results and solutions were proposed.

Various studies remain to be carried out, on the level of characterization with some proposals to widen the effectiveness of our method, in particular if the material ferroelectric is deposited on a metal substrate, as on the level of the temperature measurement which remains still a vital subject since it would make it possible to test stability electronic circuits in different environments.

The interest in tunable applications, open the way to advance towards the study of new characterization methods in the goal of integration of thin layers in the realization of controllable devices at ultra high frequencies, thus minimizing the price, volume and losses of today's' electronic circuits.

\section{References}

Al-Shareef H.N., Dimos D., Raymond M.V. And Schwartz R.W. (1997), Tunability and Calculation of the Dielectric Constant of Capacitor Structures with Interdigital Electrodes, Journal of Electroceramics Vol. 1, Issue 2, pp. 145-153, ISSN: 1573-8663.

Baker-Jarvis J., Janezic M.D. (1994), Analysis of an open-ended coaxial probe with lift-off for non-destructive testing, IEEE Transactions on instrumentation and measurements, Vol. 43, No. 5, ISSN: 0018-9456.

Coakley Kevin J., Splett Jolene D., Janezic Michael D. And Kaiser Raian F. (2003), Estimation of Q-Factors and Resonant Frequencies, IEEE Transactions On Microwave Theory And Techniques, Vol. 51, No. 3, pp. 862-868, ISSN: 0018-9480. 
De Blasi, S. Queffelec, P. (2008), Non-Destructive Broad-Band Characterization Method of Thin Ferroelectric Layers at Microwave Frequencies, 38th European Microwave Conference EuMC, pp. 793-796, ISBN: 978-2-87487-006-4, The Netherland, 27-31 Oct. 2008, IEEE, Amsterdam.

Esteban J. and Rebollar J. M. (1991), Characterization of corrugated waveguides by modal analysis, IEEE Trans. Microwave Theory Tech., vol.39,pp. 937-943, ISSN: 0018-9480.

Farnell G.W., Cermak I.A., Silvester P. and Wong S.K. (1970), Capacitance and Field Distributions for Interdigital Surface-Wave Transducers, IEEE Transaction on Sonics and Ultrasonics, Vol. 17, Issue 3, pp. 188-195, ISSN: 0018-9537.

Gagwu chen, Kang Li, and Zhong Ji (1994), Bilayer dielectric measurement with an openended coaxial probe, IEEE Transactions On Microwave Theory And Techniques, Vol. 42, No. 6, ISSN: 0018-9480.

Hinojosa J, Lmimouni K., Lepilliet S. and Dambrine G. (2002), Very high broadband electromagnetic characterization method of film-shaped materials using coplanar, Microwave and Optical Technology Letters, vol. 33 n5, pp. 352-355, ISSN: 1098-2760.

Hinojosa J., Faucon L., Queffelec P., and Huret F. (2001), S-parameter broadband measurements of microstrip lines and extraction of the substrate intrinsic properties, Microwave Opt Technol. Letters Vol. 30,Issue 1,pp. 65-69, ISSN: 1098-2760.

Janezic Michael D. (2004), Broadband complex permittivity measurements of dielectric substrates using a split-cylinder resonator, Microwave Symposium Digest, IEEE MTTS International Publication, Vol. 3, pp. 1817- 1820, ISSN: 0149-645X.

Janezic Michael D., Williams D. F., Blaschke V., Karamcheti A., and Chang C. S. (2003), Permittivity Characterization of Low-k Thin Films From Transmission-Line Measurements, IEEE Transactions On Microwave Theory And Techniques, Vol. 51, No. 1, pp. 132-136, ISSN: 0018-9480.

Kassem H., Vigneras V., Lunet G. (2007), Non destructive dielectric characterization of thin ferroelectric films materials using coplanar line structure, Integrated Ferroelectrics, Vol. 94, Issue 1, pp. 82-93,ISSN: 1607-8489.

Lamkaouchi K, Balana A, Delbos G and Ellison W J (2003), Permittivity measurements of lossy liquids in the range 26-110 GHz, Institute Of Physics Publishing Measurement Science And Technology, Meas. Sci. Technol. 14, pp. 444-450, ISSN: 0957-0233.

Lue H-T Ting and Tseng T-Y, (2001), Application of on-wafer TRL calibration on the measurement of microwave properties of Ba0.5Sr0.5Ti O3 thin films, IEEE Transaction on ultrasonics, Ferroelectrics and Frequency Control, vol. $48 \mathrm{n}^{\circ} 6$, pp. 1640-1647, ISSN: 0885-3010.

Mathai C J, Saravanan S, Anantharaman M R, Venkitachalam S and Jayalekshmi S (2002) Characterization of low dielectric constant polyaniline thin film synthesized by ac plasma polymerization technique, J. Phys. D: Appl. Phys. 35 pp. 240-245, , ISSN: 0022-3727.

Mathew K.T. \& Raveendranath U. (2001), Cavity Perturbation Techniques for Measuring Dielectric Parameters of Water and Other Allied Liquids, Sensors Update -Wiley interscience, Volume 7 Issue 1, pp. 185-210, ISSN: 1616-8984.

Misra M., Kataria N.D., Murakami H. and Tonouchi M. (2003), Analysis of a flip-chip bonded tunable high-temperature superconducting coplanar waveguide resonator using the conformal mapping technique, Superconductor Science and Technology, Vol. 16, pp. 492-497, ISSN: 0953-2048. 
Nicolson, A. M. and Ross, G. F. (1970), Measurement of the intrinsic properties of materials by time domain techniques, IEEE Transactions on Instrumentation and Measurement, Vol. 19, Issue 4, pp. 377-382, ISSN: 0018-9456.

Obrzut J. and Nozaki R. (2001), Broadband Characterization of Dielectric Films for PowerGround Decoupling, Proceedings of the 18th IEEE Instrumentation and Measurement Technology Conference, IMTC, Page(s):1000 - 1004, ISBN: 0-7803-6646-8, Hungary, 05/21/2001 - 05/23/2001, Budapest.

Park Jaehoon, Lu Jiwei, Stemmer Susanne, York Robert A. (2005), Microwave dielectric properties of tunable capacitors employing bismuth zinc niobate thin films, journal of applied physics, Vol. 97, Issue 8, ISSN: 1089-7550.

Petrov P. K., Alford N. and Gevorgyan S. (2005), Techniques for microwave measurements of ferroelectric thin films and their associated error and limitations, Measurement Science And Technology Vol. 16, Issue 1, pp.583-589, ISSN: 0957-0233.

Quéffélec P., Le Floc'h M. and Gelin Ph., (2000), New method for determining the permeability tensor of magnetized materials in a wide frequency range, IEEE Transactions on Microwave Theory and Techniques, Vol. 48,No. 8, pp. 1344-1351, ISSN: 0018-9480.

Quéffélec P., Le Floc'h M. and Gelin Ph. (1999), Nonreciprocal cell for the broad band measurement of tensorial permeability of magnetized ferrites, IEEE Transactions on Microwave Theory and Techniques, Vol. 47, No. 4, pp. 390-397, ISSN: 0018-9480.

Queffelec P., Le Floc'h M., Gelin P. (1998), Broad-band characterization of magnetic and dielectric thin filmsusing a microstrip line, IEEE transactions on Instrumentation and measurements, Vol. 47, Issue: 4, pp. 956-963, ISSN: 0018-9456.

Queffellec Patrick, Gelin Philippe (1994), A microstrip device for the broadband simultaneous measurement of complex permeability and permittivity, IEEE transactions on magnetics Vol.30, No.2, pp. 224-231, ISSN: 0018-9464.

Raj A., Holmes W.S. and Judah S.R. (2001), wide band width measurement of complex permittivity of liquids using coplanar lines, IEEE Transactions on instrumentation and measurement vol.50, No. 4, pp. 905-909, ISSN: 0018-9456.

Salahun Erwan, Quéffélec Patrick, Le Floc'h Marcel, and Gelin Philippe (2001), A Broadband Permeameter for "in situ" Measurements of Rectangular Samples, IEEE Transactions On Magnetics, Vol. 37, No. 4, pp. 2743-2745, ISSN: 0018-9464.

Shenhui Jing; Ding Ding; Quanxing Jiang (2003), Measurement of electromagnetic properties of materials using transmission/reflection method in coaxial line, The $3^{\text {rd }}$ Asia pacific Conference on Environmental Electromagnetics CEEM 2003, pp. 590-595, ISBN: 7-56350802-3, China, 4-7 Nov. 2003,IEEE, Hangchou.

Simons Rainee N. (2001), Coplanar Waveguide Circuits, Components, and Systems, John Wiley and Sons, Inc. ISBN: 978-0-471-16121-9, Newyork.

Su H. T., Lancaster M. J., Huang F. and Wellhofer F. (2000), Electrically Tunable Superconducting Quasilumped Element Resonator Using Thin-Film Ferroelectrics, Microwave And Optical Technology Letters, Vol. 24, No. 3, pp. 155-158, ISSN: 10982760.

Vanzura Eric J., Baker-Jarvis James, Janezic Michael D. (1994), Intercomparison of permittivity measurements using the transmission/reflection method in 7-mm coaxial transmission lines, IEEE Transactions On Microwave Theory And Techniques, Vol. 42, No. 11, pp. 2063-2070, ISSN: 0018-9480. 
Vasundara V. Varadan, K. A. Jose, and Vijay K. Varadan (2000), In situ Microwave Characterization of Nonplanar Dielectric Objects, IEEE Transactions On Microwave Theory And Techniques, Vol. 48, No. 3, pp. 388-394, ISSN: 0018-9480.

Vyacheslav V. Komarov \& Vadim V. Yakovlev (2003), Modeling Control Over Determination Of Dielectric Properties By The Perturbation Technique, Microwave And Optical Technology Letters, Vol. 39, No. 6, PP. 443-446, ISSN: 1098-2760.

Weir, W. B. (1974), Automatic measurement of complex dielectric constant and permeability at microwave frequencies, Proceedings of the IEEE, Vol. 62, Issue 1, pp. 33-36, ISSN: 0018-9219.

Zhao Ji-Xiang (2005), Characteristic Parameters For Cpws On A Very Thin Dielectric Layer, Microwave \& Optical Technology Letters, Vol.45, No.3,pp. 240-241,ISSN: 1098-2760. 


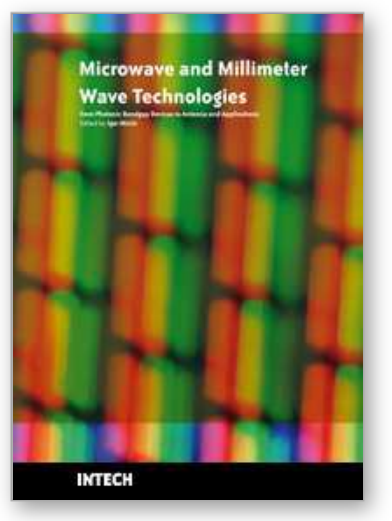

\section{Microwave and Millimeter Wave Technologies from Photonic Bandgap Devices to Antenna and Applications \\ Edited by Igor Minin}

ISBN 978-953-7619-66-4

Hard cover, 468 pages

Publisher InTech

Published online 01, March, 2010

Published in print edition March, 2010

The book deals with modern developments in microwave and millimeter wave technologies, presenting a wide selection of different topics within this interesting area. From a description of the evolution of technological processes for the design of passive functions in milimetre-wave frequency range, to different applications and different materials evaluation, the book offers an extensive view of the current trends in the field. Hopefully the book will attract more interest in microwave and millimeter wave technologies and simulate new ideas on this fascinating subject.

\section{How to reference}

In order to correctly reference this scholarly work, feel free to copy and paste the following:

Hussein Kassem, Valerie Vigneras and Guillaume Lunet (2010). Characterization Techniques for Materials' Properties Measurement, Microwave and Millimeter Wave Technologies from Photonic Bandgap Devices to Antenna and Applications, Igor Minin (Ed.), ISBN: 978-953-7619-66-4, InTech, Available from:

http://www.intechopen.com/books/microwave-and-millimeter-wave-technologies-from-photonic-bandgapdevices-to-antenna-and-applications/characterization-techniques-for-materials-properties-measurement

\section{INTECH}

open science | open minds

\section{InTech Europe}

University Campus STeP Ri

Slavka Krautzeka 83/A

51000 Rijeka, Croatia

Phone: +385 (51) 770447

Fax: +385 (51) 686166

www.intechopen.com

\section{InTech China}

Unit 405, Office Block, Hotel Equatorial Shanghai

No.65, Yan An Road (West), Shanghai, 200040, China

中国上海市延安西路65号上海国际贵都大饭店办公楼 405 单元

Phone: +86-21-62489820

Fax: $+86-21-62489821$ 
(C) 2010 The Author(s). Licensee IntechOpen. This chapter is distributed under the terms of the Creative Commons Attribution-NonCommercialShareAlike-3.0 License, which permits use, distribution and reproduction for non-commercial purposes, provided the original is properly cited and derivative works building on this content are distributed under the same license. 